Tadeusz ORZECHOWSKI ${ }^{1}$

Anna TYBURCZYK ${ }^{2}$

Kinga ZIETTALA ${ }^{3}$

\title{
WYMIANA CIEPLA PRZY WRZENIU NA ŻEBRZE Z POKRYCIEM METALOWO-WŁÓKNISTYM
}

\begin{abstract}
Praca dotyczy badań intensyfikacji wymiany ciepła przy wrzeniu na nieizotermicznych powierzchniach elementów wymiennikowych. W literaturze spotyka się wiele badań związanych z procesami wymiany ciepła przy zmianie fazy, które bardzo często dotyczą pokryć wytwarzanych różnymi technologiami. Główną wadą tych badań jest to, że głównie prowadzone są na powierzchniach izotermicznych. W artykule zaprezentowano wyniki badań działania pojedynczego żebra we wrzącym etanolu w warunkach ciśnienia otoczenia. Zastosowano kamerę termowizyjną do pomiaru rozkładu temperatury dla dwóch próbek: o gładkiej powierzchni i powłoce kapilarno-porowatej nałożonej w celu zwiększenia przejmowania ciepła. W niniejszej pracy przedstawiono badania wpływu wybranego pokrycia kapilarno-porowatego na wielkość wymiany ciepła na nieizotermicznych powierzchniach usytuowanych pionowo. Badania prowadzono na stanowisku pomiarowym, którego głównym elementem jest długie miedziane żebro, którego podstawę utrzymywano w stałej dla danej serii pomiarów temperaturze. Cieczą odbierającą ciepło był etanol pod ciśnieniem atmosferycznym. Omówiono metodykę pomiarów oraz przedstawiono wyniki badań. W oparciu o zmierzony kamerą termowizyjną powierzchniowy rozkład temperatury wyznaczono lokalne wartości odprowadzanego strumienia i współczynnika przejmowania ciepła, które pokazano w postaci krzywej wrzenia dla żebra o powierzchni gładkiej i pokrytej strukturą kapilarno - porowatą. Z porównania lokalnie odprowadzanych strumieni ciepła wynika, że największa różnica pomiędzy nimi występuje przy przegrzaniu $19 \mathrm{~K}$ i wynosi niemal $218 \mathrm{~kW} / \mathrm{m}^{2}$.
\end{abstract}

Słowa kluczowe: wrzenie, żebro, struktura kapilarno-porowata, strumień ciepła, termowowizja

${ }^{1}$ Autor do korespondencji: Tadeusz Orzechowski, Politechnika Świętokrzyska, al. Tysiąclecia Państwa Polskiego 7, 25-314 Kielce, tel. 413424 854, todek@tu.kielce.pl.

${ }^{2}$ Anna Tyburczyk, Politechnika Świętokrzyska, al. Tysiąclecia Państwa Polskiego 7, 25-314

Kielce, annazw@tu.kielce.pl.

${ }^{3}$ Kinga Ziętala, Politechnika Świętokrzyska, al. Tysiąclecia Państwa Polskiego 7, 25-314 Kielce, kzietala@tu.kielce.pl. 


\section{Wprowadzenie}

Intensyfikacja procesów wymiany ciepła $\mathrm{w}$ rożnych gałęziach przemysłu stanowi jeden z najważniejszych współczesnych problemów techniki cieplnej. W wielu dziedzinach istnieje olbrzymie zapotrzebowanie na rożnego wysokowydajne wymienniki ciepła pracujące przy niewielkich różnicach temperatur i charakteryzujące się małymi gabarytami. Wymagania takie najlepiej spełniają urządzenia wykorzystujące procesy zmiany fazy, szczególnie wtedy, kiedy dodatkowo rozwija się ich powierzchnie poprzez nakładanie różnorakich struktur.

Jedną z najprostszych i jednocześnie najbardziej rozpowszechnionych metod jest nakładanie struktur siatkowych, metalowo włóknistych, proszkowych, w tym natryskiwanych cieplnie. Wśród nich na szczególną uwagę zasługują metaliczno włókniste struktury kapilarno - porowate. Zbudowane są one z cienkich włókien różnych metali i ich stopów. Staranne nałożenie takich struktur skutkuje dużą wartością współczynnika przejmowania ciepła, przy odpowiednio dobranych parametrach takich jak: grubość, porowatość i przewodność szkieletowa.

Obszerny przegląd nad takimi powłokami podał Semena [7]. Struktury kapilarno - porowate wykonane były z metali znacznie różniących się przewodnością cieplną (m.in. miedź, nikiel i stale nierdzewne). Pomiary prowadzono dla takich cieczy wrzących jak woda, etanol, freon-22 i freon-113. Zmiennym parametrem była grubość i porowatość warstwy. Wyznaczony współczynnik przejmowania ciepła był o rząd większy od odpowiadającego mu współczynnika w obszarze konwekcji swobodnej dla powierzchni gładkiej. Poza tym wykazano, że gęstość strumienia ciepła i przegrzanie powierzchni grzejnej, dla których dochodzi do przejścia z obszaru parowania do wrzenia pęcherzykowego, zależą od charakterystyk struktury kapilarno-porowatej oraz właściwości cieplnych wrzącej cieczy.

Wrzenie na powierzchniach z pokryciem metalowo włóknistym przebiega inaczej niż na powierzchniach gładkich. Tłumaczy się to specyficznymi warunkami wymiany ciepła w warstwie pokrywającej powierzchnię grzejną. Według [2] wrzenie pęcherzykowe na powierzchni gładkiej związane jest z centrami nukleacji, którymi są zagłębienia lub rysy, otoczone przegrzaną warstwą cieczy o grubości równej około średnicy odrywającego się pęcherza. Wymiana ciepła odbywa się przez konwekcję i parowanie. Natomiast w przypadku warstwy porowatej wrzenie odbywa się wewnątrz struktury, a ciepło przewodzone jest od powierzchni grzejnej do elementów mikrostruktury przez przewodzenie $\mathrm{w}$ szkielecie.

Pomimo, iż struktury kapilarno-porowate są jednymi z efektywniejszych konstrukcji, dalsze nakładanie powłok o większych grubościach napotyka na barierę zasilania kapilarnego cieczą. Utrudnia to również transport ciepła do wyżej położonych elementów. 
Dużą niedogodnością w pełnym wykorzystaniu badań opisanych w literaturze jest to, że dotyczą powierzchni izotermicznych i zwykle zorientowanych poziomo. Rzeczywiste układy wymiennikowe są nie tylko nieizotermiczne, ale też są konstruowane w różnej orientacji przestrzennej. Np. wg [1] zmiana nachylenia powierzchni z poziomego do pionowego skutkuje nawet ponad 100\% zmianą przy umiarkowanych gęstościach strumienia ciepła. Podobne różnice uwidaczniają się pomiędzy izotermiczną powierzchnią grzejną i nieizotermiczną - np. powierzchnią żebra. W efekcie obliczenia prowadzone dla powierzchni wymiennikowych, w których występuje gradient temperatury, z wykorzystaniem zależności literaturowych nie dają wystarczająco dobrych rezultatów przy projektowaniu urządzeń do zastosowań technicznych. Takie badania porównawcze przeprowadzono dla żeber o powierzchni technicznie gładkiej. Przedmiotem badań eksperymentalnych były gładkie żebra wykonane z miedzi i aluminium pracujące w wodzie i etanolu pod ciśnieniem atmosferycznym. Dla takich powierzchni wyznaczono analogiczne krzywe wrzenia wykorzystujące korelacje: Rohsenowa, Labuntsova i Kruzhilina [6]. Wykonane porównanie własnych wyników eksperymentalnych ze wspomnianymi zależnościami literaturowymi wykazało znaczne rozbieżności [3] i [4]. Przy czym najmniej odbiegającą i dającą najlepsze wyniki była korelacja Rohsenowa.

Celem niniejszej pracy są badania wymiany ciepła przy wrzeniu etanolu na przykładzie powierzchni nieizotermicznej długiego miedzianego żebra o powierzchni pokrytej metalowo włóknistą strukturą kapilarno-porowatą o zadanych parametrach mikrostruktry.

\section{Opis stanowiska pomiarowego}

Badania prowadzono na specjalnie do tego celu zestawionym stanowisku, którego uproszczony schemat pokazano na rysunku 1.

Głównym jego elementem jest płaskie żebro o przekroju prostokątnym. Jest ono zamontowane pomiędzy dwiema bocznymi bakelitowymi płytami, które stanowią obudowę naczynia wypełnionego wrzącą cieczą. Żebro od strony płynu zostało jednostronnie pokryte strukturą intensyfikującą wymianę ciepła (metalowo włóknistą strukturą kapilarno-porowatą). Badania prowadzono w warunkach stacjonarnych przy ustalonej, lecz różnej dla każdej serii pomiarowej temperaturze u podstawy żebra. Niezbędne ciepło doprowadzano za pomocą głównego grzejnika elektrycznego zasilanego z autotransformatora. Celem podtrzymania wrzenia w całej objętości naczynia zastosowano układ grzejnika pomocniczego, gdzie elementem grzejnym jest drut oporowy ułożony spiralnie na dnie naczynia. Dla wszystkich serii pomiarowych utrzymywano stałą moc elektryczną dostarczaną w układzie grzejnika pomocniczego. Chłodzenie par i odzysk kondensatu realizowany był w oddzielnym układzie dwóch chłodnic, 
których temperaturę stabilizowano w układzie otwartym miejską wodą sieciową.

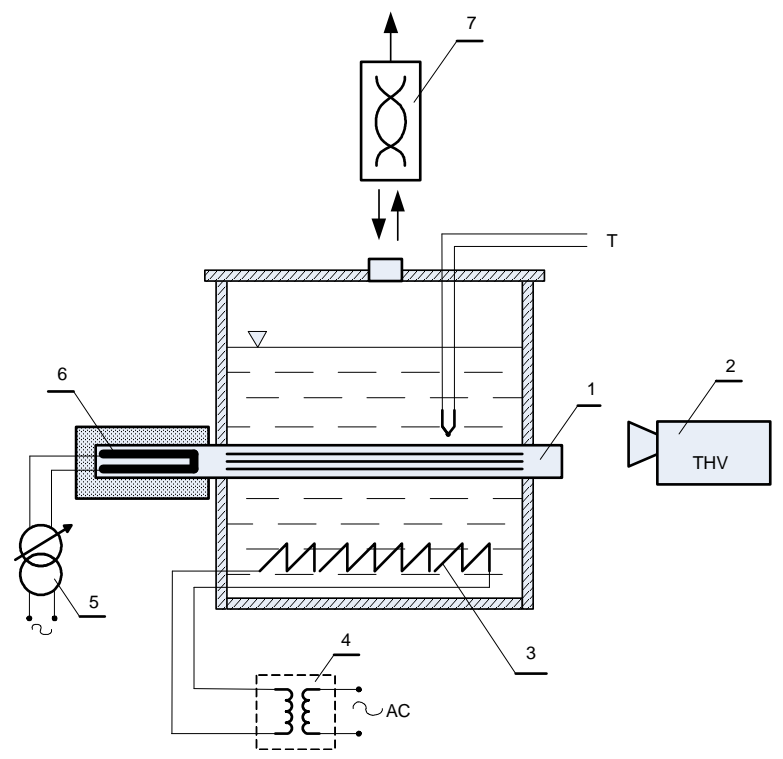

Rys. 1. Schemat stanowiska pomiarowego: 1 - badany element, 2 - kamera termowizyjna, 3 grzałka pomocnicza, 4 - układ grzejnika pomocniczego, 5 - autotransformator z pomiarem mocy elektrycznej, 6 - grzejnik główny, 7 - układ zasilania cieczą i odzysku kondensatu, T - termopara

Fig. 1. Schematic of measuring position: 1 - the examined element, 2 - the thermographic camera, 3 - the auxiliary heater, 4 - auxiliary heater system, 5 - the autotransformer with the electric power measurement, 6 - the main heater, 7 - the liquid supply and condensate recovery system, $\mathrm{T}$ - thermocouple

Przedmiotem pomiaru jest powierzchniowy rozkład temperatury na żebrze od strony zewnętrznej, który mierzono kamerą termowizyjną VarioCAM® hr. Kamera jest wyposażona w niechłodzoną macierz bolometryczną o formacie obrazu 640 x 480 pikseli. Urządzenie przeznaczone jest do pracy w długofalowym zakresie promieniowania podczerwonego $7,5 \div 14 \mu \mathrm{m}$. Badania prowadzono ze standardowym obiektywem kamer $(30 \times 23)^{0}$. Obserwowaną powierzchnię równomiernie pokryto czarną farbą w celu zapewnienia jednorodności optycznej zewnętrznej powierzchni badanych próbek.

Zestawiony układ pomiarowy umożliwia przyjęcie założenia o jednowymiarowości zjawiska, tj. przyjęcie, że zmiana temperatury po grubości żebra jest pomijalnie mała. Założenie to jest słuszne dla liczb $\mathrm{Bi}<0,1$. Wynikiem badań jest jednowymiarowy rozkład temperatury po długości żebra wzdłuż jego osi. 


\section{Wyniki i metodyka badań}

Badania wykonano dla próbki miedzianej, na którą napieczono metaliczno włóknistą warstwę kapilarno-porowatą o parametrach: wysokości $\mathrm{h}_{\mathrm{w}}=1 \mathrm{~mm}$ i porowatości objętościowej 85\%. Strukturę wykonano z pociętego drutu o średnicy $0,05 \mathrm{~mm}$ i długości włókien $\sim 3 \mathrm{~mm}$, które napieczono w redukcyjnej atmosferze wodoru. Czynnikiem odbierającym ciepło był etanol pod ciśnieniem atmosferycznym. Dla celów porównawczych i kalibracyjnych wykonano również pomiary w identycznych warunkach dla miedzianego żebra o powierzchni gładkiej.

Wynikiem obserwacji kamerą termowizyjną zewnętrznej powierzchni badanego elementu jest pole termalne. Na rysunku 2 przedstawiono przykładowy poosiowy rozkład temperatury wzdłuż badanego żebra przy stałej mocy grzejnika głównego dla dwóch próbek: o powierzchni gładkiej oraz z nałożoną strukturą kapilarno-porowatą. Analizując poniższy rysunek można zauważyć, iż nałożenie pokrycia włóknistego intensyfikuje wymianę ciepła w stosunku do powierzchni gładkiej. Ze względu na odpowiednio duże wymiary jej wychłodzenie do temperatury wrzenia cieczy następuje przed połową wysokości próbki. Obserwuje się to dla wszystkich serii pomiarowych, które wykonywano przy różnych mocach elektrycznych przyłożonych u podstawy grzejnika głównego.

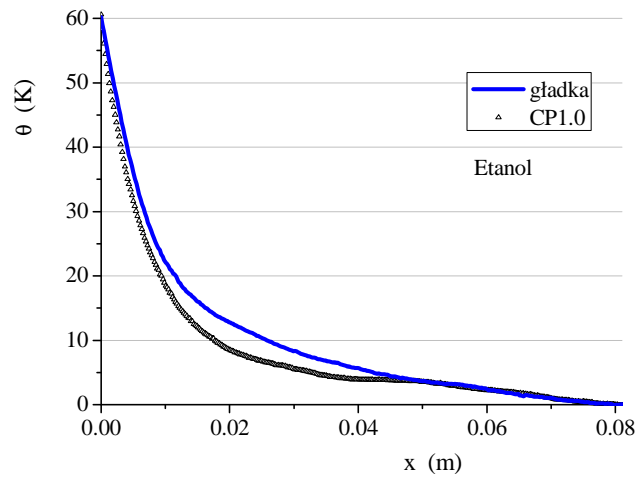

Rys. 2. Rozkład temperatury na miedzianym żebrze wzdłuż jego linii środkowej przy stałej mocy grzejnika głównego dla próbki gładkiej i kapilarno - porowatej o wysokości warstwy 1,0 mm

Fig. 2. Temperature distribution along the centerline of the cooper fin at constant heating power of main heater for smooth and capillary-porous layer of a height of $1.0 \mathrm{~mm}$

Wynikiem pomiaru kamerą termowizyjną jest duża ilość punktów pomiarowych, co zezwala na zastosowanie metody numerycznego różniczkowania z jednoczesnym wygładzaniem. W ten sposób wyznaczono pochodną dla dwóch badanych próbek po długości żebra, którą pokazano na rysunku 3. Jest ona proporcjonalna do ilości transponowanego ciepła wzdłuż długości elementu. Warto 
zauważyć, że wartość tej pochodnej jest prawie równa zeru w odległości poniżej połowy wysokości żebra.

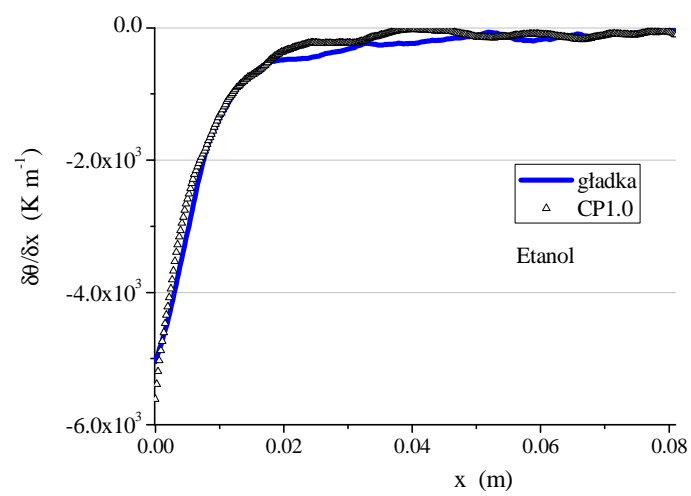

Rys. 3. Gradient temperatury w funkcji długości dla próbki gładkiej i kapilarno - porowatej

Fig. 3. The temperature gradient versus lenght for the smooth and capillary-porous sample

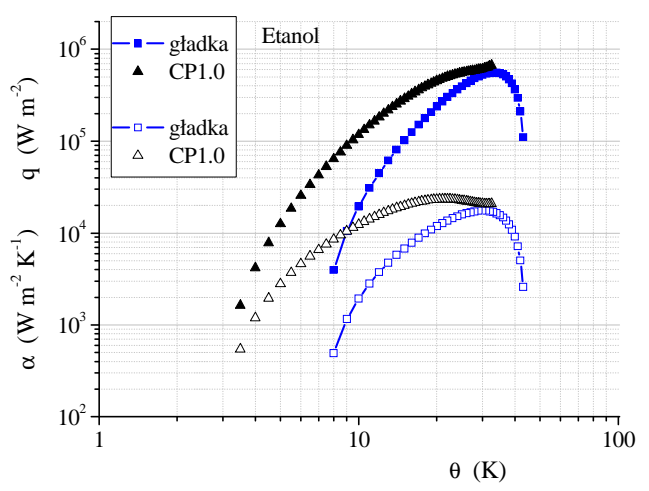

Rys. 4. Krzywa wrzenia dla próbki gładkiej i z nałożoną metaliczno włóknistą strukturą kapilarno - porowatą

Fig. 4. Boiling curve for smooth sample and sample with capillary-porous structure of coating

Przedstawioną na rysunku 3 pochodną wykorzystuje się do obliczenia lokalnie odprowadzanych strumieni ciepła, a w konsekwencji wyznaczenia krzywej wrzenia dla rozpatrywanego elementu o nieizotermicznej powierzchni. Wynik takich obliczeń dla próbki gładkiej i z pokryciem kapilarno-porowatym zaprezentowano na rysunku 4. Szczegółową procedurę obliczeń opisano w pracy [5]. 


\section{Wnioski}

Końcowym wynikiem prowadzonych badań jest zależność lokalnie odprowadzanych strumieni oraz współczynników przejmowania ciepła dla żebra o powierzchni gładkiej oraz z kapilarno-porowatym pokryciem. Jak pokazano na wykresie 4 wrzenie pęcherzykowe rozpoczyna się przy przegrzaniu $\sim 8 \mathrm{~K}$ dla próbki o powierzchni gładkiej, zaś dla próbki z pokryciem strukturalnym już przy $\sim 3,5 \mathrm{~K}$. Podobne przesuniecie w kierunku niższych przegrzań obserwuje się dla maksymalnych wartości strumienia ciepła. W tabeli 1 zamieszczono lokalne wartości gęstości strumienia ciepła przy jednakowym przegrzaniu. Obliczono również różnicę pomiędzy tymi wartościami dla obydwu próbek, która początkowo rośnie, a dla wyższych przegrzań maleje. Obserwuje się maksimum $\Delta \mathrm{q}=\mathrm{q}_{\text {kapilarno-porowata }}-\mathrm{q}_{\text {gladka }}=217,7 \mathrm{~kW} / \mathrm{m}^{2}$ przy przegrzaniu $19 \mathrm{~K}$.

Tabela 1. Gęstość strumienia ciepła przy stałym przegrzaniu

Table 1. Heat flux at constant superheat

\begin{tabular}{|c|c|c|c|c|c|}
\hline $\mathrm{q}\left(\mathrm{kW} / \mathrm{m}^{2}\right)$ & $\theta=10 \mathrm{~K}$ & $\theta=13 \mathrm{~K}$ & $\theta=19 \mathrm{~K}$ & $\theta=26 \mathrm{~K}$ & $\theta=29 \mathrm{~K}$ \\
\hline $\mathrm{q}_{\text {gładka }}$ & 19,3 & 61,3 & 206,9 & 425,0 & 502,8 \\
\hline $\mathrm{q}_{\text {kapilarno-porowata }}$ & 117,5 & 217,2 & 424,6 & 566,7 & 599,6 \\
\hline $\boldsymbol{\Delta q}$ & $\mathbf{9 8 , 2}$ & $\mathbf{1 5 5 , 8}$ & $\mathbf{2 1 7 , 7}$ & $\mathbf{1 4 1 , 7}$ & $\mathbf{9 6 , 8}$ \\
\hline
\end{tabular}

\section{Literatura}

[1] Nishikawa K., Fujita Y.: Nucleate Boiling Heat Transfer and Its Augmentation. Hartnett J.P., Irvine, Jr., T.F.(ed.), Academic Press, Advances in Heat Transfer, 20 (1990), pp. 1-82.

[2] O'Neill P.S., Gottzmann C.F., Terbot J.W.: Heat Exchangers for NGL. Chem. Eng. Prog., vol. 67, 1971.

[3] Orzechowski T., Zwierzchowska A., Zwierzchowska S.: Wymiana ciepła na żebrach z metalowo włóknistym pokryciem kapilarno-porowatym. Inżynieria i Aparatura Chemiczna, 6 (2009), s. 144-145.

[4] Orzechowski T., Zwierzchowska A., Zwierzchowska S.: Evaluation of boiling heat transfer coefficients on fin's smooth surface. Transcom 2009: 8-th European Conference of Young Research and Scientific Workers. Zilina June 22-24, 2009 - Slovak Republic. Ed. by Alan Vaško, Peter Brida, Copyright by University of Žilina, 2009, pp. 169-172.

[5] Orzechowski T.: Determining local values of the heat transfer coefficient on a fin. Experimental Thermal and Fluid 31 Issue: 8 (2007) pp. 947-955.

[6] Pioro I.L., Rohsenow W., Doerfer S.S.: Nucleate pool-boiling heat transfer. II: assessment of prediction methods. International Journal of Heat transfer 47 (2004) pp. 5045-5057. 
[7] Semena M.G., Geršuni A.N., Zaripov V.K.: Teplovye truby s metallovoloknistymi kapiljarnymi strukturami. Višč. Škola, Kiev, 1984.

\section{BOILING HEAT TRANSFER ON A FIN WITH CAPILLARY-POROUS COATINGS}

\section{S u m m a r y}

The paper deals with boiling heat transfer intensification on non-isothermal heat exchanger surfaces. Many researches related to heat transfer with phase change on coatings produced by different technologies are reported in the literature. The disadvantage of these researches is that the results are presented for mainly isothermal surfaces, while the real heat exchanger units are usually non-isothermal and heat transfer processes proceed differently in relation to isothermal conditions. The paper presents the results of investigations into a single fin operating in ethanol boiling under ambient pressure. Thermographic camera was used to measure temperature distribution for two specimens: with a smooth surface and capillary-porous coating superimposed to enhance heat transfer. This paper presents the results of study on the impact of the selected capillary-porous coating on the size of non-isothermal heat transfer surfaces oriented vertically. The tests were conducted on the measuring position, whose main element is a long copper fin, which was kept at a constant temperature for series of measurements. Heat receiving fluid was ethanol at atmospheric pressure. The measurement methodology is discussed and the results of the research are presented. Based on the measured by using thermographic camera surface temperature distribution the local values of stream carrying away and the heat transfer coefficients are determined. These results are shown as a boiling curve for a fin with a smooth surface and coated of capillary - porous structure. The maximum difference in the locally rejected heat flux at $19 \mathrm{~K}$ superheat is observed an equals $218 \mathrm{~kW} / \mathrm{m}^{2}$ nearly.

Keywords: boiling, fin, capillary-porous structure, hat flux, infrared mapping

DOI: $10.7862 / \mathrm{rm} .2014 .26$

Otrzymano/received: 20.05.2014

Zaakceptowano/accepted: 22.06 .2014 